\title{
A Holistic Theoretical Sustainability Assessment Model for Electricity Generating Sources
}

\author{
Ndala Yves Mulongo and Clinton Aigbavboa \\ Faculty of Engineering and the Built Environment \\ University of Johannesburg, South Africa
}

\begin{abstract}
In response to ever-increasing concerns regarding ecological degradation and societal impact, numerous stakeholders such as non-governmental organisations, government officials, end-users, the mass media, and community activists have compelled business organizations, particularly multi-national companies to lessen harmful greenhouse gases emissions associated with their production activities. Energy sector is one of the biggest harmful greenhouse gases emission producer, hence, decision-makers within the energy sector are forced to promote and build environmental friendly and sustainable power generation plants. To this end, the concept of sustainability in the electricity sector has attracted so much attention from academics and industrial practitioners over the last three decades. Albeit, an important number of sustainability assessment frameworks for electricity generating technologies are found in the current literatures, three major drawbacks have emerged from those frameworks. Firstly, there is a lack of a holistic and comprehensive sustainability assessment framework for different power generation plants. Secondly, from economic aspect, the most used model (Levelised Cost of Electricity) to measure the cost performance of various electricity generating technologies is biased and is not inclusive enough, because, it only considers the capital, Operations and Maintenance, and fuel costs. Hence, snubbing crucial elements to business decision. Lastly, in the current literature, there is no a single sustainability assessment model that considers all the phases of electrical energy's lifecycle. Considering these flaws, the novelty of this study is the development of a new, holistic theoretical sustainability assessment framework for power generation plants. The developed theoretical model includes 19 impact categories, 52 potential indictors, and 10 end points environmental, economic, and social aspects.
\end{abstract}

\section{Introduction}

Energy in the form of electricity production plays a critical role in the development of a country alongside with other manufacturing firms. A sustainable plan of electrical energy generation could enhance economy, human being's lifestyle and social wellbeing of a nation (Maxim, 2014). Over the past three decades, there has been a growing concern regarding ecological degradation and societal impact, numerous stakeholders such as nongovernmental organisations, government officials, end-users, the mass media, and community activists have led to the development of the sustainable development concept that is designed with the aim of meeting the needs of the present generation without compromising the ability of future generations to meet their own needs. Thus, various business organizations, particularly multi-national companies have been compelled to lessen harmful greenhouse gases emissions associated with their production activities. Energy sector is one of the biggest harmful greenhouse gases producer, hence, decision-makers within the energy sector are also compelled to promote and build environmental friendly and sustainable power generation plants. However, complying with such requirement generally involves the measurement of financial, ecological and social performance of power generation plants. Albeit, an important amount of sustainability frameworks for electricity supply systems have been developed in the current literatures over the past decade, there is a lack of a comprehensive and integrated sustainability assessment framework for power generation plants. Study under sustainable electrical energy production diverges with regard to sundry aspects such as deepness of analysis, technological level, time-based and environmental distribution, and means employed in assessing and integrating various sustainability pillars (Santoyo-Castelazo and Azapagic, 2014). Appendixes A, B1 and B2 review a set of of 183 studies that have conducted in the field of sustainability energy development within different countries across the globe. The reviewed studies were published over 1997-2017, indicating the accrued knowledge of the past two decades.

\subsection{Background}

Regardless of being panned for definitional elusiveness and haziness (Lele, 1991), the notion of sustainability has become a crucial subject within the business environment. Nevertheless, the long argument around the definition of sustainability, in the researcher environment there is an increasing agreement that present study attempts ought to change towards emerging tangible means for encouraging and quantifying sustainable accomplishments (Veleva and Ellenbecker, 2001). Within the electricity sector this concern is even more serious and vital because of the massive and sundry impact the sector has got over other industries, community, and environment, generating 
financial and societal benefits. However, meanwhile causing important issues and harmful externalities, such as pollution of the atmosphere and consequently contributing to global warming phenomenon. In accordance with Orsato and Wells (2007) the construction of sustainable electricity generating sources ought to cover a comprehensive model involving an equilibrium among societal, technical, ecological and financial features regarding the end-product or service development process. Despite the fact that the need for promoting and measuring sustainability practices within the electricity sector has attracted so much attention from academic and industrial practitioners over the last three decades, the current models, blueprint and frameworks, developed by both researcher within academic environment and industrial practitioners, actually, the existing frameworks within the current body of knowledge seek to study ecological, financial and societal features alongside the end-product life cycle in segregation from each other (Jasinski et al., 2016 ). Hence, in order to address the existing flaws in the current literature on sustainability appraisal in electricity sector, a critical literature review was conducted with the purpose of reviewing and classifying the existing body of knowledge resulting partly the methodical literature survey process regularly used within the management and organization researches (Tranfield et al., 2003). Precisely, a research procedure was exploited including a clear definition and detailed aims of the literature analysis, screening phase, and appraisal on the basis of segregation and insertion standards, tailed by an analysis of the recognised features of the gathered contents. The overall goal of conducting this critical appraisal of current literature was to find out to what extent sustainability analysis for different electricity generating technologies has been developed from a holistic perspective, and in which context does electricity sector regard sustainability.

\section{Theoretical framework}

To commence with the critical appraisal of existing literature review on sustainability assessment of power generation plants, the ISI Web of Science database was used with 'sustainability in electricity sector' used as keywords. The time frame was from 1997-2017. The search only focused on peer-reviewed articles published in English, falling under certain subject areas. The search resulted in 389 documents that were thoroughly scrutinised by means of a of titles and abstracts with the purpose of developing additional boundaries and eliminating incorrect and/or unrelated entries (screening phase). Throughout this phase, groups of inclusion and segregation standards were established, versus which individually every singly journal article was evaluated. Precisely, articles assessed are those, which clearly considers sustainability analysis frameworks developed for power generation plants, and those that used sustainability appraisal to processes or materials related to other industries than power sector considering either single, two or all three sustainability pillars (environmental, social, economic) whilst assessing sustainability. It should be pointed out that studies that did not meet these norms were not taken into account. This stage generated 183 studies focusing on power generation plants and 20 studies focusing on other industries that electricity sector, were judged to be important for additional thorough scrutiny. Afterward, in order to respond to the main goal of this study, which is of developing a new, integrated sustainability assessment framework for power generation plants, the 183 studies were labelled on the basis of a set of standards, involving the general type of sustainability analysis used, the lifecycle phases (i.e, extraction of raw material, transportation of raw material, conversion of raw material into electricity, transmission and distribution of electricity to end-users); sustainability pillars taken into account (i.e. environmental, economic, and social aspects), the type of indicators used to assess the economic, environmental, and social impacts of different power generation plants. As it is demonstrated in the Appendixes A; B.1 and B.2. The outcomes of the critical appraisal of literature review generated various conclusions, first and foremost in current decade there has been a significant growth regarding the number of articles published related to sustainability in the electricity industry. Renewable Sustainable Energy Reviews was most represented in the literature review, with 61 of the 183 journal articles, followed by Energy Policy with 52 articles, Journal of Cleaner Production ranks at the third position with 28 articles, Energy with 25 articles, Applied Energy 21, Sustainability 14, Energies 10, Technological Forecasting and Social Change 9, and Renewable Energy 7 articles. Whereas, the remaining of the appropriate journals were just about equally distributed with low frequency (1-6 articles). Furthermore, the results of literature survey revealed that $77 \%$ of studies performed in electricity sector focused separately either on economic, environmental, or social aspects of power plants, while $7 \%$ attempted to combined only two aspects, and only $16 \%$ of the works attempted to incorporate all the three sustainability pillars into one framework. Supporting the idea that the electricity sector would benefit from a holistic and comprehensive framework for sustainability assessment.

\section{Conceptual framework}

Considering the gaps identified in the existing literature through the analysis of 183 journal articles, this study as addressed those flaws by developing a new, holistic sustainability analysis framework for electricity generating sources, as demonstrated by the figure 1 below. The developed model includes 19 impact categories, 52 potential indictors, and 10 end points environmental, economic, and social aspects. 


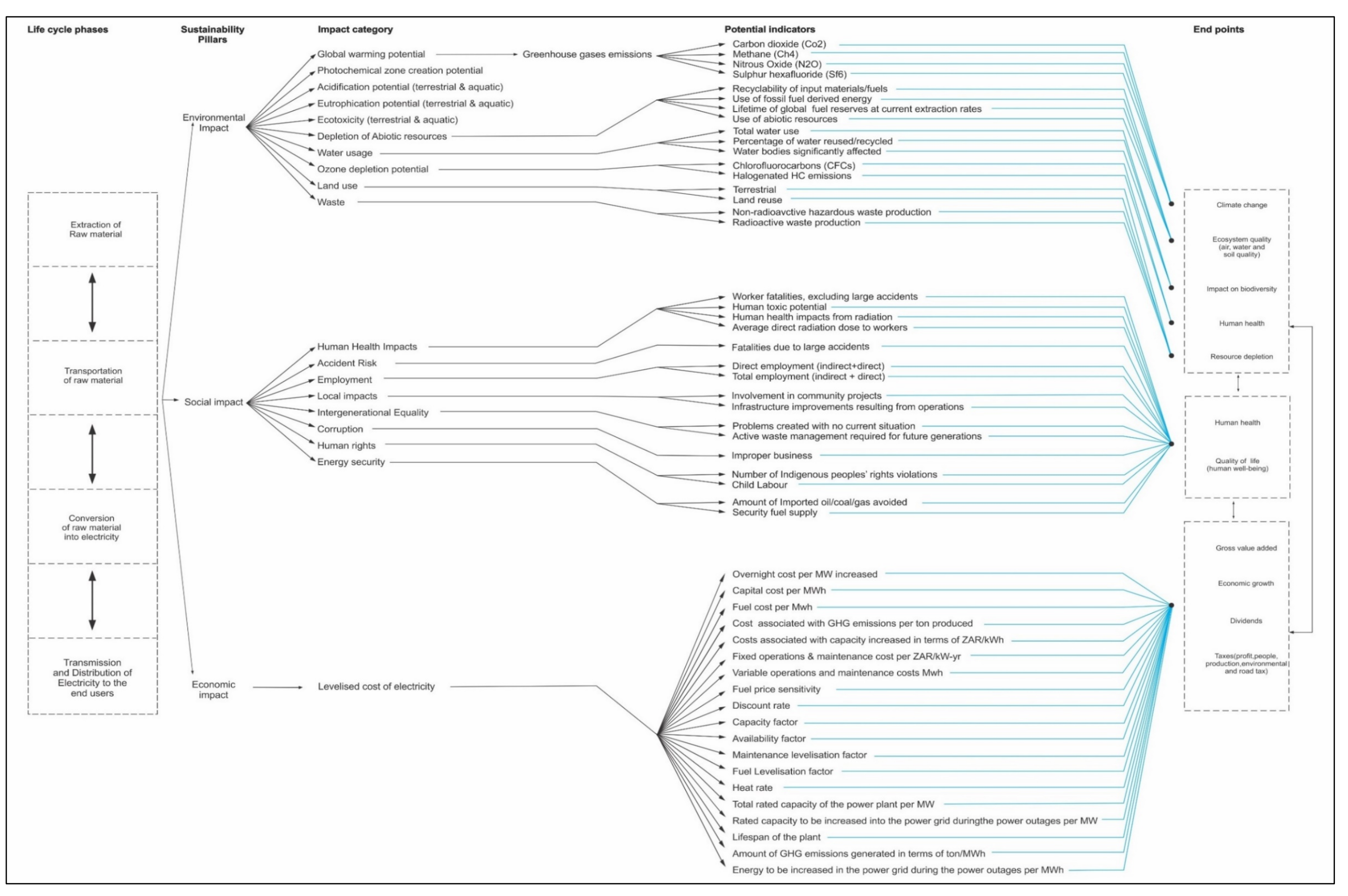

Figure 1: Theoretical sustainability assessment framework for power generation plants (constructed based on the literature survey)

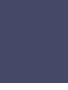

(1) The

$$
\text { y) }
$$

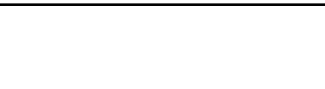

(1) 


\subsection{Economic pillar}

The outcomes of the literature analysis that from economic impact, Levelised Cost of Electricity (LCOE) is a metric that is largely employed by decision makers in energy sector to measure the cost performance of various electricity generating sources options. Unfortunately, the current LCOE model is naïve and is not inclusive enough since it is a mere summation of capital, Operations and Maintenance, and fuel costs. Hence, ignoring some elements that are crucial to business decision. An additional issue that was observed with the standard LCOE model is that it is only applicable to electricity production options, which use akin technologies with the same annual energy production (Megawatt-hours) as determined by capacity factor. To provide a fair cost assessment between various power production technologies and to address gaps containing in the current LCOE model, this study has developed a novel LCOE model that incorporates critical components to business decision such as, lifecycle greenhouse costs, Transmission and Distribution costs, and rated capacity replacement costs during power crisis. Thus, the below lines will thoroughly present the LCOE as well as the novel LCOE model developed in this study based on the flaws identified in the literature survey.

\subsubsection{The Levelized Cost of Electricity (LCOE)}

Despite capital cost is a critical element that influences the cost associated with producing electrical energy by means of a power plant. There exist also others. As we will address them later in this chapter, such as fuel costs that is a key factor for fossil fuel-based power production stations. And also, costs related to operating and maintaining a power plant is also crucial, mainly in those that employ technologies such as gas turbines that necessitate recurrent important repairs. In what way, then, does one organised concerning merging all these factors to calculate the cost of producing a unit of electrical energy through a recommended power plant? Here the response is by employing certain form of financial modelling. Considering this, LCOE is the economic modelling that is widely used by many decisions makers. This includes computing the overall cost invested in the construction and operation of the plant throughout its whole lifespan, divided for every single year of its operation. The yearly outlays are afterward discounted to adapt them into the present worth. All the yearly discounted figures are then totalled in order to offer a figure in current's currency for the overall costs related to the power plant. This number is divided by means of the projected overall production of the plant during its lifespan and the resulting figure is the LCOE from the plant, once more in the current's values.

The LCOE approach is an important tool for an economic assessment of various electricity generation technologies and it is the most consulted method in electricity sector when investment and planning decisions are to be made (Mulongo (2017) from Guzmán, et al 2015; Hisham, 2015; Parrado et al 2015). Furthermore, it represents the most transparent approach being used for power planning and policy development (IEA/NEA, 2010). The reason for this being the most used methodology is because it allows cost comparison of several forms of electricity generation, which differ from physical principles, fuel types, and their lifespan (Mulongo (2017) from Klein 2009; Murat \& Mustafa, 2009; Fluri, 2009; Francesco, 2015). When calculating the LCOE of a power plant, all discounted direct plant costs over the lifespan of the plant are divided by the discounted sum of the electricity that it would produce over its lifespan (Mulongo (2017) from Gross et al 2007; Hisham 2015; Simon et al 2013; IEA/NEA 2010; DECC 2013). In the context of financial, LCOE may also be defined as the constant level of inflows important per year in order to recover all outflows over the lifespan of a power plant (Mulongo (2017) from Roth \& Ambs, 2004; NREL, 2010). In the standard method, these outflows involve capital costs, Operation \& Maintenance costs (O\&M), and fuel costs. In the end, the calculation enables a cost comparison among various alternatives over a constant unit cost basis; in this study ZAR/MWh has been used. Practically, there are two methods that can be used to determine LCOE of a power plant, namely the simplified LCOE method (sLCOE) and the Financial Model Approach (FMA). These two approaches are different because the sLCOE method determines "the minimum price at which electricity should be marked for an electricity generation plant to break even (either have present worth of zero)" whereas the FMA "determines the needed inflows in order to achieve a certain internal rate of return" of a particular investor (Black and Veatch, 2011). This internal rate of return depends on industry-specific project discount rates, tax liability, financing expenses and incomes requirements. Therefore, FMA approach is largely used by integrated industries, which may have to make some internal investment decisions among various power generation technologies (Black \& Veatch, 2011). On the other hand, sLCOE method is mainly used by policy makers because it allows a cost comparison for several power investment technologies without taking into account a specific requirement, which differ from one industry to another industry and thus a single discount rate for all projects is used (Gross et al, 2007, Klein 2009, Simon et al 2013, Black \& Veatch, 2011). For these reasons and also because industry specific data are always hard for outsiders to obtain, the sLCOE approach was adopted for this study.

\section{A. Standard LCOE model}

Typically, as mentioned above the current LCOE model takes into account three cost components: 


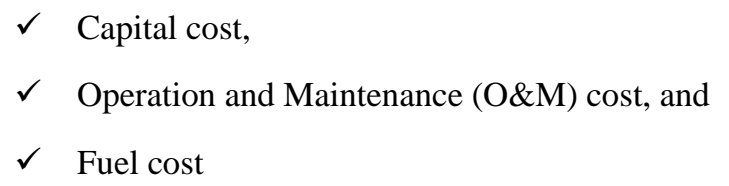

In the following lines, these three cost factors will be separately explored and then mixed into a standard LCOE formula.

\section{Financing capital cost}

The cost of constructing a power plant should typically be achieved at the kick-off of the project, or at least once it is terminated. In many instances, nowadays this would include rising a finance loan to be reimbursed through the purchase of the electrical energy the plant generates (Gross et al 2007; Hisham 2015; Simon et al 2013; IEA/NEA 2010). The timespan during which the loan is paid back relies upon its magnitude and on the kinds of electricity plant under construction. Generally, it is expected to be less than 2 decades. This is insignificant than the anticipated lifespan of the majority of contemporary electricity plants. Coal and gas power plants are likely to have a lifespan of about 3 decades, despite in certain circumstances this might be prolonged with an important overhaul. While, nuclear technologies are now expected to run for nearly 4 decades, some perhaps lengthier. Huge hydro-power stations are expected to have lifespan beyond 5 decades on condition that the site is well selected. In case, the time-scale of loan does not concur with an accurate lifespan for a plant, the outcome is a reimbursement timetable, which may negatively impact on the financial side of the project by means of gathering the outlay of the electrical energy it produces (Gross et al 2007; Hisham 2015; Simon et al 2013; and IEA/NEA 2010).

In case, for instance, a hydro-power plant has a lifespan of 5 decades could merely gather a building loan to be repaid over 2 decades, in this case the electrical energy produced by means of this plant throughout the timeframe of the lend refund would be much significant than it may be if the lend repayment period is estimated at 4 decades. This is particularly real of RES that are normally capital demanding since lend reimbursements regularly form the main component of the cost associated with generating electrical energy (Irene et al, 2017; Ishan and Pallav, 2017; Ivan et al, 2016). On the other hand, a lend for a low-priced gas power plant would be much simpler to reimburse, albeit operating outlay might be much larger. There seems to be no resources of evading this blow of finances under the circumstances that function in economic markets currently whereby stakeholders request short refund timeframe and important revenues. Given that it influences capital investment more harshly does irrationally hinder certain RES, nevertheless, there are certain indications that this is being established now at a governmental level (Irene et al, 2017; Ishan and Pallav, 2017; Ivan et al, 2016)

Furthermore, capital cost is an important key for calculating LCOE of a power plant, and it is generally based on the Plant costs (that are described as the costs set up to build a power plant). Generally, for such analysis, the idea of overnight costs is considered, which has been defined by Klein (2009); Simon et al (2013), EUSUSTEL (2007), and Murat \& Mustafa (2009) as the costs that are incurred for the construction of a power plant immediately, and it does not take into account any assumptions upon interest expenses that happen during the construction period. Often, such data is designed on the basis of currency per unit of capacity, as all costs must be levelized over a unit of electricity produce, e.g. in ZAR/MWh. According to Daniel, et al (2013); EPRI (2012); Guzmán, et al (2015); and IEA/NEA (2010) plant costs should be divided by the amount of electricity produce within a year. This is given by the 8760 , that is the number of hours in one year, which are multiplied by the total size of the plant and the capacity factor of the plant stating the percentage of the time the power plant actually produces electricity. For example, a power plant that has a rated capacity of $4800 \mathrm{MW}$, when operating with an 85\% capacity factor, generates $35740800 \mathrm{MWh}$ per year. It is important to notice that no power plant can operate at capacity factor of $100 \%$. Since regular maintenance should be done and over time some components will be replaced, and the maintenance process will require the plant to stop (Paul, 2010; Jason, 2011). So far, this illustration is for capital cost per unit of power produce during one year. As matter of fact, a power plant runs over decades. That is why a Capital Recovery Factor (CRF) must be taken into consideration. Leland \& Anthony (2012) describe CRF as the equivalent annual amount that the asset, process, or system has to earn each year just to recover the initial investment at a specified discount rate over its expected life. The CRF thus converts a flow of annual payments over the lifespan of the plant into a present value. It depends on the discount rate applied to the project and plant operation time. Thus, the standard capital cost per unit of electricity produced is calculated according to the below equation:

$$
C P / M W h=\sum\left[\frac{\left(C_{O} R_{c}\right) \times\left(\frac{r(1+r)^{l_{t}}}{(1+r)^{l_{t}}-1}\right)}{\left(R_{c} \times l_{f} \times h_{a-y r s}\right)}\right]
$$


Where:

$\checkmark \quad$ CP : Capital cost per MWh produced

$\checkmark \quad C_{O}$ : Overnight cost per MW increased

$\checkmark \quad R_{c}$ : Total rated capacity of the power plant

$\checkmark \quad l_{f}$ : Load factor

$\checkmark \quad r$ : Discount rate

$\checkmark \quad l_{t}$ : Lifespan of the power plant

$\checkmark \quad h_{a-y r s}$ : Number of hours within a year

\section{Operation and Maintenance (O\&M) cost}

O\&M costs are the costs that are incurred for the operation of a power plant and generally are expressed in terms of fixed or variable. Fixed O\&M costs are the costs that do not depend on the generated amount of electricity (Mulongo (2017) from Klein, 2009; IEA/NEA, 2010). Generally, they are set up for the things like loan payment, required maintenance, site security and staff (Klein, 2009). Fixed O\&M costs are designed on the basis of currency per unit $\$ / \mathrm{kW}$ (for South Africa is ZAR/kW) (EPRI, 2012). Like the plant costs the fixed O\&M costs are as well divided by annual electricity produce in order to determine how much of them take place during one year of production (EPRI, 2012). Whilst, Variable O\&M costs depend on the generated amount of electricity, these costs are set up for the things like fuel costs, additional staffing, and additional maintenance (Mulongo (2017) from Klein, 2009; EUSUSTEL, 2007). Usually, they are presented as ZAR/MWh. The O\&M cost of a power plant is calculated according to the equation below:

$$
O \& M_{C} / M W h=\sum\left[\frac{\left(F_{O M} \times R_{c}\right)}{\left(R_{c} \times l_{f} \times h_{a-y r s}\right)}+V_{O M}\right]
$$

Where:

$\checkmark \quad O \& M_{C}$ : Operations and Maintenance costs per unit of electricity produced

$\checkmark \quad F_{O M}$ : Fixed operations and maintenance costs

$\checkmark \quad V_{O M}$ : Variable operations and maintenance costs

$\checkmark \quad R_{c}$ : Total rated capacity of the power plant

$\checkmark \quad l_{f}$ : Load factor

$\checkmark \quad h_{a-y r s}$ : Numer of hours within a year

\section{Fuel cost}

Fuel cost is the cost of fuel, most often designed on the basis of currency per megawatt-hour. For a thermal power plant, it is the heat rate (Btu/kWh) multiplied by the cost of the fuel (ZAR/MMBtu). This involves upfront fuel costs, and also the on-line operating fuel usage (Mulongo (2017) from Klein, 2009). Allowance is made in the calculation for the degradation of a power plant's heat rate over time. Fuel costs are not considered for renewable energy (Fluri, 2009). The fuel cost per unit of electricity produced is calculated according to the equation below:

$$
F_{c} / M W h=\sum\left(f_{p} \times H_{r t}\right)
$$

Where:

$\checkmark \quad F_{c}$ : Fuel cost per unit of electricity produced

$\checkmark \quad f_{p}$ : Fuel price

$\checkmark \quad H_{r t}$ : Heat rate of the plant 
When we include all these components, we can therefore calculate the LCOE per unit of electricity generated according to the equation below:

$$
\begin{aligned}
\text { LCOE } / M W h= & \sum\left[\frac{\left(C_{O} R_{c}\right) \times\left(\frac{r(1+r)^{l_{t}}}{(1+r)^{l_{t}}-1}\right)}{\left(R_{c} \times l_{f} \times h_{a-y r s}\right)}\right]+\sum\left[\frac{\left(F_{O M} \times R_{d}\right)}{\left(R_{c} \times l_{f} \times h_{a-y r s}\right)}+V_{O M}\right] \\
& +\sum\left(f_{p} \times H_{r t}\right)
\end{aligned}
$$

This standard LCOE formula has been used by various studies such as, Black \& Veatch (2011), Branker, et al (2011), Carlo (2014), Daniel, et al (2013), EPRI. (2012), Guzmán, et al (2015), Hisham (2015), IEA/NEA (2010), Khatib (2014), Lazard (2015), Parrado, et al (2015), Simon et al (2013), WEC (2013), Jason (2011), Murat \& Mustafa (2009), Fluri, (2009), Francesco, (2015), Zhao, et al (2015), Umberto \& Pietro (2014). Klein (2009), EUSUSTEL (2007), and DECC (2013). However, the issue with this standard LCOE model is that is simply based on the summation of capital, O\&M, and fuel costs associated with the power plants, thus, ignoring some elements that are becoming more and more crucial when it comes to make business decision. Therefore, in this study, we have modified the standard LCOE formula by developing a novel LCOE model that considers the omitted factors (costs associated with GHG emissions, and costs associated with the rated capacity and energy to be increased in the power grid throughout the power outages).

\section{B. Novel LCOE model}

To provide a fair cost assessment between various power production technologies and to address gaps containing in the current LCOE model, this study has developed a novel LCOE model that incorporates critical components to business decision such as, lifecycle greenhouse costs, Transmission and Distribution costs, and rated capacity replacement costs during power crisis. Thus, the below lines will thoroughly present the LCOE as well as the novel LCOE model developed in this study based on the flaws identified in the literature survey.

$$
\begin{aligned}
\text { LCOE } / M W h= & {\left[\sum\left[\frac{\left(C_{O} R_{c}\right) \times\left(\frac{r(1+r)^{l_{t}}}{(1+r)^{l_{t}}-1}\right)}{\left(P A_{e f f} \times H A_{\text {eff }}\right)}\right]+\sum\left[\frac{\left(F_{\text {OM }} \times R_{d}\right)}{\left(P A_{\text {eff }} \times H A_{\text {eff }}\right)}+\gamma \times V_{O M}\right]+\sum \delta \times\left(\frac{f_{p} \times H_{r t}}{\beta_{\text {eff }}}\right)\right] } \\
& +\sum_{i} C_{i} \times M_{p i}+\sum \frac{\left(R D_{C} \times \Delta R\right)+\left(E R_{C} \times \Delta E\right)}{\left(P A_{\text {eff }} \times H A_{\text {eff }}\right)}
\end{aligned}
$$

Where:

$\checkmark \quad P A_{\text {eff }}$ : Annual effective plant output

$\checkmark \quad H A_{\text {eff }}$ : Annual effective plant operating hours

$\checkmark \quad$ : Maintenance levelisation factor

$\checkmark \quad \delta \quad$ : Fuel levelisation factor

$\checkmark \quad \beta_{\text {eff }} \quad$ : Effective rated efficiency

$\checkmark \quad C P$ : Capital cost per MWh produced

$\checkmark \quad C_{O}$ : Overnight cost per MW increased

$\checkmark \quad R_{d}$ : Total rated capacity of the power plant

$\checkmark \quad r$ : Discount rate

$\checkmark \quad l_{t}$ : Lifespan of the power plant

$\checkmark \quad f_{p}$ : Fuel price

$\checkmark \quad H_{r t}$ : Heat rate of the plant

$\checkmark \quad O \& M_{C}$ : Operations and Maintenance costs per unit of electricity produced

$\checkmark \quad F_{O M}$ : Fixed operations and maintenance costs 


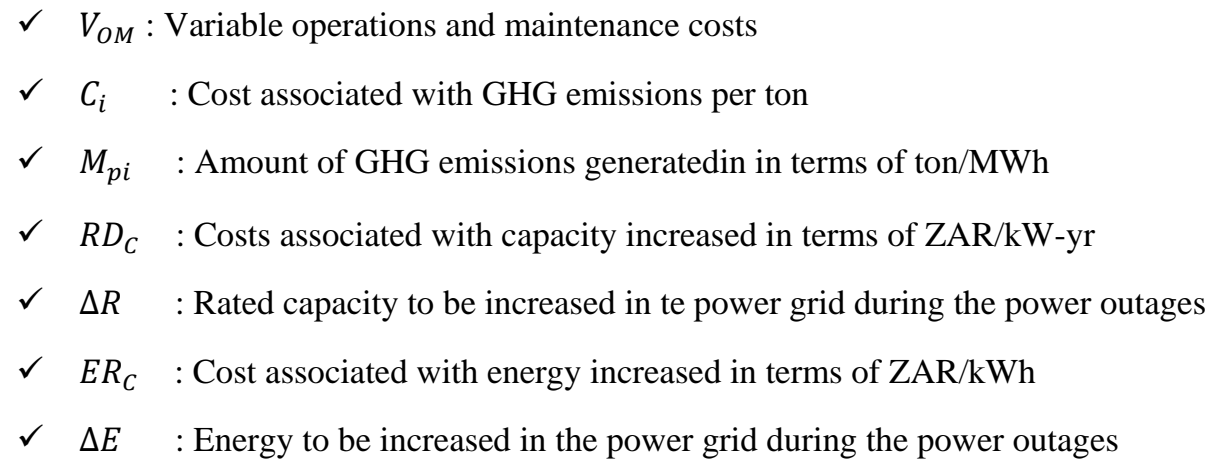

It should be noted that the rated capacity and energy replacement accounts for the change concerning effective overall GW production and output, which should be supplied in case there is a dearth in electrical energy (MWh or GWh) ought to be made up adding in the power grid an additional plant when a deficit in capacity (MW or GW) ought to be made up through a purchase of fixed capacity from neighbouring grid. Additionally, in this new LCOE model we have added levelisation factors associated with the O\&M and fuel costs is because both factors are always subjected to a growth during the lifespan of the plant.

\subsection{Environmental pillar}

The electricity sector is the largest source of ecological smog. Therefore, it is crucial to take into account all the impacts associated with environmental regardless of the present focus on global warming, as trade-offs regularly apply. In order to guarantee as wide analysis of ecological effects as possible, the subsequent environmental indicators are considered in this study:

\section{A. Global Warming Potential (GWP)}

GWP is a driving-factor of the energy policy. Many governments across the world is aiming to considerably reduce CO2 in the environment by 2050. Santoyo-Castelazo et al (2014); Sharon and Stephanie (2015); and Tarun and Balachandra (2015) reported that in 2013 the output of worldwide's electrical energy and amounted to more than 32 billion tons of CO2 equal to atmosphere, or 26\% of the overall CO2 emissions through financial sector in 2010 (Oliveira et al, 2015; Onat and Bayar, 2010; Xiaoyu et al, 2011; Padey et al, 2012). This is a growth of nearly 55.4\% since 1990 as argued by Sastre et al (2015); Schleisner (2000); Sean et al (2015); Sebastian et al (2011); Sharon and Stephanie (2015); and Sheng et al (2016). RES is generally viewed as an alternative for mitigating the current global warming issues. Nevertheless, not all renewable energy generating source is greenhouse gas-free. For example, among the studies presented in the appendixes A some of them argue that wind turbines and photovoltaic cells do not generate carbon dioxide during their operations, however during their construction, installation and recycling process some amount of CO2 emissions are emitted in the atmosphere. This goes the same with the dams of hydropower technology, which generate some of GHG emissions during their construction as well as operation mostly due to the degeneration of organic material in the dam. Most of this takes place within anoxic areas inside the dam, leading to the development of anaerobic methane during degeneration process.

Nations such as South Africa and United States that heavily rely on fossil fuels to produce electricity have Higher level of GHG emissions related to the development of wind turbines and photovoltaic cells. Hence, a conventional power grid mix for that particular country must clearly be defined regarding the type of GHG emissions. For example, GHG emissions for a specific American power grid exceed 31\%, and this greater when compare to the one of Europe. In addition, GHG emissions generated through photovoltaic cells are higher due to important fossil-fuel to produce electrical energy. Some studies conducted an assessment regarding the use of only renewable energy source to generate electrical energy to operate a plant manufacturing wind turbines or photovoltaic cells. Suat and iftcioglu (2013); Suwanit and Gheewala (2011); Talavera et al (2017); Tarun and Balachandra (2015); and Thu and John (2015) state that employing photovoltaic power to provide electrical energy for manufacturing photovoltaic modules lower the overall CO2 emissions of a thin film module by 83\% to only $7.1 \mathrm{~g} \mathrm{CO2/kWh}$. Xiaolong et al (2014); Xiaoye et al (2013); Xuecheng et al (2017); Yaw et al (2014); Yemane et al (2017); and Yemane and Getachew (2017) pointed out that GWP can be calculated according to the following equation:

$G W P=\sum_{i}^{i} G W P_{i} Y_{i}\left(k g C O_{2-e q} / k W h\right)$ 
Where:

$\checkmark \quad$ GWP : overall GWP of a power production plant expressed in (kg CO2-eq/kWh)

$\checkmark G W P_{i}$ : factor regarding GHG emission expressed in (kg CO2-eq/kg)

$\checkmark \quad Y_{i} \quad$ : emission related to GHG

$\checkmark \quad$ i:overall amount of GHG

\section{B. Photochemical Oxidant Creation Potential (POCP)}

POCP of ethylene is associated with the potential of volatile organic compounds (VOCs) as well as NOx, CH4 and CO in producing photochemical or summer smog. Turconi et al (2014); Valentina et al (2015); Vargas et al (2015); Viebahn and Nitsch (2007); Vuk et al (2016); Wang and Sun (2012); and Warner and Heath (2012) argued that POCP can be calculated according to the following equation:

$$
P O C P=\sum_{i}^{i} \operatorname{POCP}_{i} Y_{i}\left(C_{2} H_{4}-e q / k W h\right)
$$

Where:

$\checkmark \quad$ POCP : overall photochemical oxidant creation potential of a power plant (kg ethylene-eq/kWh)

$\checkmark \quad P_{i} P_{i}$ : Ability of genus (kg C2H4-eq/kg)

$\checkmark \quad Y_{i} \quad$ : emission of particles causative to the development of summer smog $(\mathrm{kg} / \mathrm{kWh})$

$\checkmark \quad$ i: overall amount of particles participating to the development of summer smog

\section{Acidification Potential (AP)}

AP is among one of the biggest reason of growing death of marine creatures in seas and rivers, and also attrition of constructions because of emissions of acid gases such as $\mathrm{SO}_{2}, \mathrm{NOx}, \mathrm{HCl}$ and $\mathrm{NH}$. In South Africa, the electricity sector is considered as one of the major producers of these gases since at least $95 \%$ of electricity is generated from conventional electricity generating sources such as coal, nuclear, and gas. To this end, Carla et al (2017); Carlo et al (2016); Carlo et al (2015); Carlos et al (2016); Carrera and Mack (2012); Chao et al (2014); and Changqing et al (2016) stated that AP is calculated in accordance with the formula below:

$$
A P=\sum_{i}^{i} A P_{i} Y_{i}\left(k g S O_{2-e q} / k W h\right)
$$

Where:

$\checkmark A P$ : total acidification potential of power generation plant (kg SO2-eq/kWh)

$\checkmark A P_{i}:$ acidification potential related to acid gas (kg SO2-eq $/ \mathrm{kg}$ )

$\checkmark \quad Y_{i}$ : emission associated with acid gas $(\mathrm{kg} / \mathrm{kWh})$

$\checkmark \quad$ i: overall amount associated with acid gases

\section{Eutrophication Potential}

EP denotes the increase of biomass within the environment because of a glut of nutrients such as nitrogen and phosphorus. In return, the domestic oxygen as well as marine creatures are diminished. Presently, in South Africa, serious tons are topped in 62\% of households' sensitive to eutrophication as of nitrogen production (DoE, 2010). Additionally, this is also outlined, together with AP, as a critical concern of ever-growing significance due to power plants without CCS generated quite a lot of NOx and NH3. To this end, Alexandru (2014); Alvaro et al (2015); Amit et al (2017); Andrew et al (2011); Arvesen and Hertwich (2012); and Arvesen et al (2015) reported that EP is calculated in accordance with the formula below: 


$$
E P=\sum_{i}^{i} E P_{i} Y_{i}\left(k g P O_{4-e q}^{3-} / k W h\right)
$$

Where:

$\checkmark \quad E P$ : total eutrophication potential related to power generation plant $\left(\mathrm{kgPO}_{4-e q}^{3-} / \mathrm{kWh}\right)$

$\checkmark E P_{i}$ : eutrophication potential associated with particles $\left(\mathrm{kg} \mathrm{PO}_{4-e q}^{3-} / \mathrm{kg}\right)$

$\checkmark \quad Y_{i}$ : emission associated with nutrient $(\mathrm{kg} / \mathrm{kWh})$

$\checkmark$ i: overall amount associated with nutrients

\section{E. Water use}

In accordance with Turnpenny \& Coughlan (2003) power sector uses more that $50 \%$ of the overall water consumption within the industrialised and developing countries. When a country has a dry climate, water reserve is an important means for that specific country, therefore, it should be wisely used. Most of forms of electricity producing sources need important amount of water for cooling. Literature regarding water usage and overall withdrawal throughout electrical energy production are illustrated in Tamim et al (2009); Herbert (2004) Evans et al (2009); Heidi et al (2017); Hong et al (2013); Irene et al (2017); and Juan et al (2015). The utilisation of water viewed as the evaporation or vanished from the system, which is impossible to be recovered. Furthermore, withdrawal is considered as the overall amount needed for the operation of a technology and including water accessible for recycling process. With nearly $1 \mathrm{~g}$ of water consumed/kWh, the consumption of water by wind is insignificant. Solar PV also consume insignificant litter of water estimated at $10 \mathrm{~g} / \mathrm{kWh}$. Because of these very insignificant figures, wind and photovoltaics are considered to be more environmental friendly and sustainable regarding the usage of water. The conclusions made based on the findings by Herbert (2004) about geothermal are very different from the results obtained by Tamim et al. (2009), who found that the usage of water turning around $1.7 \mathrm{~kg} / \mathrm{kWh}$. Water use concerning geothermal fluctuates largely, depending upon the effectiveness of water capture and recycling processes including the heat of the geothermal means. It is, therefore, possible to build a closed system with geothermal electricity production plant, which can meet the lowest limits demonstrated.

In contrast, coal and gas illustrate an equal water withdrawal estimated at $78 \mathrm{~kg}$ water $/ \mathrm{kWh}$, since, both technologies consume huge amount of water for cooling process. Herbert (2004) reported that water usage for coal and gas is approximately $1.6 \mathrm{~kg} / \mathrm{kWh}$ that reflect the findings published by the Australian Bureau of Statistics findings of Dennis (2006), which were evaluated at $1.5 \mathrm{~kg} / \mathrm{kWh}$ for coal electricity generating source. However, it much lower than the conclusions of Tamim et al (2009), who estimated at $14-28 \mathrm{~kg} / \mathrm{kWh}$. In addition, Dennis (2006) estimated the value for gas technology at $0.6 \mathrm{~kg} / \mathrm{kWh}$ that significantly much lower than coal. It should be noted that the consumption of water by Biomass is larger than coal and gas, due to the fact that the combustion process of biomass uses the same quantity of water, however, there is also the added water load of crop increase (if applicable), collecting and transportation of a low energy dense fuel and drying of a high moisture fuel.

Additionally, it was estimated by Herbert (2004) that constant energy crops have a water conditions that is more 10 times greater than waste residue biomass. He also reports that the usage of water of about $1.8 \mathrm{~kg} / \mathrm{kWh}$ is needed to generate electricity through biomass, which is once more less compared to the outcomes presented by Tamim et al. (2009) that ranges between 31-75 kg/kWh. Nuclear electricity generation source has a significant requirement regarding water cooling process within the reactors. Of all the power generating sources, hydropower has the highest water consumption, as it needs an important water volume to be stored. In this case, storage ends in water diminution within the dam through evaporation, the scale of which is impacted by the overall dam surface area and volume, local heat, and geography.

Herbert (2004) reported that the average water evaporation from dams is approximately $19 \mathrm{~kg} / \mathrm{kWh}$. Whereas, Tamim et al. (2009) came up with the findings that is the loss of water through evaporation is very low, evaluated at $0.26 \mathrm{~kg} / \mathrm{kWh}$. Dennis (2006) presented the findings that much more compared Tamim et al. (2009); and Herbert (2004), with an average of water withdrawal of around $3740 \mathrm{~kg} / \mathrm{kWh}$ in many sites in which hydropower is implemented in Australia, but, he also reported that almost the amount of this water is employed in-stream and not used. Thus, impacts concerning water quality are numerous, varying from the emission of lethal mixtures to temperature growth. Two environmental metrics emerged from these impacts: freshwater and marine eco-toxicity potentials. Both indicators are expressed in 1,4-dichlorobenzene (DCB) equivalents per kWh. Herbert (2004) and Tamim et al (2009) argued these indicators that calculated in accordance with the formula below: 


$$
\begin{aligned}
& \text { FWETP }=\sum_{i}^{i} F W E T P_{i} Y_{i}(k g 1,4-D B C-e q / k W h) \\
& M E T P=\sum_{i}^{i} M E T P_{i} Y_{i}(k g 1,4-D C B-e q / k W h)
\end{aligned}
$$

Where:

$\checkmark$ FWETP: overall freshwater eco-toxicity potential of power production plant $(k g 1,4-D B C-$ $e q / k W h)$

$\checkmark \quad$ FWETP $_{i}$ : freshwater eco-toxicity potential of particle $(\mathrm{kg} 1,4-D B C-e q / \mathrm{kg})$

$\checkmark$ METP: overall marine eco-toxicity potential related to power production plant $(\mathrm{kg} 1,4-D B C-$ $e q / k W h)$

$\checkmark \quad$ METP $_{i}$ : marine eco-toxicity potential of particle $(\mathrm{kg} 1,4-D B C-e q / \mathrm{kg})$

$\checkmark \quad Y_{i}$ : emission associated with particle to freshwater or seawater $(\mathrm{kg} / \mathrm{kWh})$

$\checkmark$ i: overall amount of lethal particles

\section{F. Land use}

Land is a kerbed product, especially in nations with large population densities such as South Africa. The land needed for the construction of power plants is a significant matter for the assessment of power generation plants (Edgar and Arturo, 2013; Eduard et al, 2012; Eduard et al, 2015; Elvira et al, 2012;Begic' and Afgan, 2007 \& Burcin and Adisa, 2016). The ecosystem and landsite are impacted directly by the land used to build power plant. Land use is also viewed as a social criterion to analyse the electricity generation plant. It is characterised as one of the most important aspects for the intervention site, particularly where the daily mankind activities are important issues of environmental strain (Grant et al, 2011; Gregory and Timothy, 2005; Guezuraga et al, 2012; Gujba et al, 2010; and Guofu et al, 2016).

The Quality of life of human beings is often influenced by power supply systems as it might have been deployed for the development of parks and recreation centres. The diggings, channels and other work essential for power plants operation threaten the vegetation, the nature and the ecology in general. Different forms of power generating resources need different land whilst the products are same. Mainly power generating stations with biomass and biofuels necessitate the huge amount of land. The size of terrain is an important component about the direct and indirect footprint zone needed. It determines the size of the soil needed for building or implementing a power generation technology. Three sustainability are involved under this category: land use, greenfield land use and terrestrial eco-toxicity. Land use is a measure of the overall land used during the entire life cycle and the period for which it is not available for other usage. Laurence and Adisa (2011) and Laurence and Adisa (2014) argued that these indicators are calculated according to the equations below:

\section{Impact of land use $(I L U)$ is calculated}

$$
I L U=\beta \times l\left(m^{2} y r / k W h\right)
$$

\section{Greenfield land use (GLU)}

GLU is referred to the ratio of the size of greenfield land that is used to build an electricity generation plant, associated with the absolute volume of zone that is planned to be used by the plant. It is computed in accordance with the formula below:

$$
G F U=\frac{G F A}{T L A}(100 \%)
$$

\section{Terrestrial eco-toxicity potential (TETP)}

TETP is referred as the all-out acceptable concentrations of lethal elements by various creatures in terrestrial environment. It is computed according to the equation below: 


$$
T E T P=\sum_{i}^{i} T E T P_{i} Y_{i}(k g 1,4-D C B-e q / k W h)
$$

Where:

$\checkmark \quad$ ILU: overall effect of power plant on land occupied over time $\left(\mathrm{m}^{2} . \mathrm{yrs} / \mathrm{kWh}\right)$

$\checkmark \quad \beta$ : the size of land used (m2)

$\checkmark \quad l$ : lifespan during which land is in used (years)

$\checkmark$ GFU: ratio of greenfield land deployed to build an electricity generation plant (\%)

$\checkmark$ GFA : the size of greenfield land occupied $\left(\mathrm{m}^{2}\right)$

$\checkmark \quad$ TLA : overall size of land consumed by an electricity generation plant $\left(\mathrm{m}^{2}\right)$

$\checkmark$ TETP: overall terrestrial eco-toxicity potential of power plant $(k g 1,4-D C B-e q / k W h)$

$\checkmark \quad T E T P_{i}$ : terrestrial eco-toxicity potential associated with harmful particle $(\mathrm{kg} 1,4-D C B-e q / \mathrm{kg})$

$\checkmark \quad Y_{i} \quad$ : emission of particle toward land $(\mathrm{kg} / \mathrm{kWh})$

$\checkmark$ i: overall amount of harmful particle discharged into the land

Lastly, it has been noticed that there is no a single sustainability assessment framework for different electricity generating technologies in the current literature that considers the entire lifecycle stages such as Extraction of RAW Material, Transportation of Raw Material, Conversion of Raw into Electricity, and Transmission and Distribution of Electricity to end-users.

\subsection{Social pillar}

The tradition of social aspect research has always been steered by the concerns of how to evaluate "quality of lifestyle" and how the elements impacting on quality of lifestyle would be sufficiently evaluated. In accordance with Bauer (1966), social metrics are described as "data, numerical series and all other forms of evidence allowing us to evaluate where we are and are going regarding our ethics and objectives (Bauer, 1966). Additionally, accentuating on the empirical aspects of metrics, Parris and Kates (2003) describe them as "quantitative indicators chosen to evaluate development toward or away from a determined objective". Garrelts and Flitner (2007) emphasize on the date function of social criteria. They claim that these metrics must be chosen to convey a wider issue with only few figures, therefore evading data excess. Though initially social criterias were developed to evaluate society' economic growth, the GNP as the major instance, social metrics are currently being approved in a comprehensive sense and are also used to appraise the technical effects, including the political stratagems. Evans et al (2009); Heidi et al (2017); and Hong et al (2013) pointed out that social aspect as being simply expressive because various studies only gather information without a fundamental theoretic concept, which preferably should lead in choosing criterion and indicators. This issue is prevalent because social metrics should not be stemmed from an overarching societal theory. A broadly acknowledged model for measuring social performance does not exist. There are various models that can be employed for social criteria, such as the quality of lifestyle, lifestyle schemas or cultural and value-related concepts. However, no fundamental theory exists allowing us to define social aspect from a comprehensible theory of what matters in society.

\section{A. Job creation.}

Many people are employed in the electricity sector, especially throughout the construction period of a power plant. This goes one from the operation until mothballing. The electricity sectors in many countries across the world are closely associated with the society. Local communities where power plants are always built depending on their development and prosperity on them for many years. Therefore, it is beneficial for the electricity utility for developing a sustainable energy system that has the potentiality for creating more jobs for citizen, additionally, it will assist in improving the lifestyle of those inhabitants (Mario et al, 2017; May et al, 2006; Mihály et al, 2014). From this category, two important sustainability metrics emerged: direct and total employ, whereby direct employs denotes the jobs generated during the life cycle of an electricity generation station, such as building, operation, upkeep and mothballing. Whilst, total employ involves indirect jobs that are created due to the plant's existence. This involves employments needed during the extraction of fuel, conveyance of fuel, processing and 
production of fuel as well as waste management. Because, the jobs created by means of a power station differs significantly depending on life cycle phase, it is important to address this sustainability indicator in terms of person-yrs (per overall electrical energy produced) instead of total amount of employments (per overall electrical energy produced) (Sharon and Stephanie, 2015; Stamford and Azapagic, 2012; Tarun and Balachandra, 2015; Widodo and Nok, 2016). For example, in case 2000 persons are hired for a period of 8 years throughout the construction of a power plant, and 1000 individuals are hired throughout the operations stage of the plant over 40 years. This gives the overall jobs created per individual-yrs is 56000 divided by the overall electrical energy generated during the entire lifetime of the power plant. Alternatively, it might be easily to aggregate the amount of employment to 3000 and divided by the amount of power produced, irrespective of the period of the contract, therefore offering merely biased employment data. To avoid this, we proposed to calculate both indicators according to the formulas below:

\section{Direct job}

$$
D J=\frac{\sum_{i}^{i} D J_{i} t_{i}}{P_{\text {tot }}}(\text { person }-y r s / M W h)
$$

\section{Indirect job}

$$
I J=\frac{\sum_{i}^{i} I_{i} t_{i}}{P_{\text {tot }}}(\text { person }-y r s / M W h)
$$

\section{Overall Job creation}

$$
O J=D J+I J(\text { person }-y r s / M W h)
$$

Where:

$\checkmark \quad D J$ : direct jobs creation during the life cycle of power plant (person-yrs/MWh)

$\checkmark D J_{i}$ : direct jobs creation over the life cycle phase

$\checkmark$ i: number of individual hired

$\checkmark \quad t_{i}$ : time associated with jobs during the life cycle phase (years)

$\checkmark \quad P_{t o t}$ : overall electricity produced throughout the lifespan of power plant (GWh)

$\checkmark \quad I J_{i}$ : indirect jobs creation over the life cycle stage

$\checkmark \quad I J$ : indirect jobs creation during the life cycle of power plant (person-yrs/MWh)

\section{B. Human Toxicity Potential (HTP)}

Power production causes numerous kinds of HTP, varying from place of work accidents to the more extensive harms related to harmful emissions. Therefore, in order to measure HTP as efficiently as possible, we suggest the subsequent three indicators, relevant during the entire life cycle of a power plant:

$>$ Employee Death Toll (EDT),

$>$ Human toxicity potential (HTP), and

$>$ Heavy Accidents Risk (HAP)

\section{Employee Death Toll (EDT)}

We refer EDT to the workforce safety, as well as suppliers and subcontractors, and it quantifies the amount of deceases per kWh of electrical energy produced. It should be noted that this metrics does not consider non-lethal accidents as death rate are more usually recorded, making the data offered by means of this indicator more precise. In light of this, we propose the equation below to calculate this indicator: 


$$
E D T=\sum_{i}^{i} E D T_{i}(n o / M W h)
$$

Where:

$\checkmark \quad E D T$ : overall number of crew mortalities

$\checkmark E D T_{i}$ : number of crew mortalities over the life cycle phase per MWh of electricity generated

\section{Human toxicity potential (HTP)}

We refer HTP to the likely detriment to people generated by lethal emissions produced over the life cycle of power plant. Akin to the ecological eco-toxicity addressed within the section on environmental indicators, it is calculated in accordance with the formula below:

$$
H T P=\sum_{i}^{i} H C A_{a i} \times B_{a i}+\sum_{i}^{i} H C W_{w i} \times B_{W i}+\sum_{i}^{i} H C S_{s i} \times B_{s i}(k g 1,4-D C B-e q / k W h)(18
$$

Where:

$\checkmark H C A_{a i}, H C W_{w i}, H C S_{s i}$, : toxicity potentials concerning harmful particles discharged in the environment (kg 1,4-DCB eq/kg).

$\checkmark \quad B_{a i}, B_{W i}, B_{s i}$ : emissions from various harmful particles $(\mathrm{kg} / \mathrm{kWh})$.

$\checkmark \quad$ i: overall amount of harmful particles to people

\section{E. Heavy Accident Potential (HAP)}

We refer HAP to the death rate caused by huge accidents throughout the life cycle of power plant and expressed per kWh of electrical energy produced. Heavy accidents in electricity sector are likely most linked to the community view regarding power production plants. For instance, the Chernobyl that is considered as the major disaster that occurred at the nuclear reactor in Ukraine in 1986. The environment was seriously polluted by the plumes of radionuclides, and this caused serious damages to human health and the environment. Furthermore, nuclear waste that is radioactive and hazardous to human health can last for many decades. This indicators is calculate according to the formula below:

$$
H A P=\sum_{i}^{i} H A P_{i}(n o / M W h)
$$

Where:

$\checkmark$ HAP: overall amount of mortalities (no./MWh)

$\checkmark H A P_{i}$ : amount of crew mortalities during the life cycle phase per unit of electrical energy generated

$\checkmark$ i: overall amount of life cycle phases

\section{F. Impact on domestic community}

This category is used to evaluate the impacts of an electricity generation plant on indigenous community. Some of the likely impacts involve jobs offer to indigenous inhabitants, and also involvement in their development and wellbeing. In light of this, the subsequent three indicators are developed out of this category that were proposed by various studies.

Percentage of crew employed from domestic community; which is associated with the absolute direct jobs offer. 
$>$ Percentage of expenditure on domestic suppliers determines the rate of outlay toward domestic community and is associated with the overall expense per annum

$>$ Direct investment in domestic community aims at promoting impartial delivery of means through direct returns to the local community [38]. This includes investments in local schools, sickbays, public services, ecological projects, etc. This social metric is addressed as proportion investment associated with the overall firm income.

Preferably, these social metrics should take into account the building, operation and mothballing phases, however it is dubious that data regarding all three phases are easily accessible at the same moment and information concerning the building and mothballing might not be accessible at all. In addition, various firms might be concerned with these three life cycle phases making it complex to get significant data. Thus, it is proposed that these metrics will merely consider the operation phase of an electricity production unit.

\section{Percentage of crew employed from domestic community}

$$
P C E D C=\frac{C E}{D C E} \times 100
$$

\section{Percentage of expenditure on domestic suppliers}

$$
P E D S=\frac{A E D S}{E_{\text {tot }}} \times 100
$$

\section{Direct investment in domestic community}

Where:

$$
D I D C=\frac{I D C}{R_{\text {tot }}} \times 100
$$

$\checkmark$ PCEDC : Percentage of crew employed from domestic community over the operation phase of the electricity generation plant

$\checkmark \quad C E$ : number of crew employed from domestic community per MWh produced

$\checkmark \quad D C E$ : overall amount of crew directly hired per GWh produced over the lifespan of the plant

$\checkmark \quad$ PEDS : percentage of expenditure on domestic suppliers

$\checkmark$ AEDS: annual expense on domestic suppliers (£/yrs)

$\checkmark \quad E_{\text {tot }}$ : overall annual expenditure associated with the O\&M of the plant (ZAR/yrs)

$\checkmark$ DIDC : Direct investment in domestic community each year (\%)

$\checkmark$ IDC : yearly investment in domestic community (ZAR/yrs)

$\checkmark \quad R_{\text {tot }}$ : overall yearly income (ZAR/yrs)

\section{G. Human rights violation and bribery}

Moral concerns associated with human rights and bribery are considered as important issues within certain nations where the social and governing governments are idle. Nevertheless, it is hard to measure this indicator within an impartial way because data regarding humans' abuses and bribery is not easily accessible. Furthermore, value decisions are essential when describing the idioms such as abuse and bribery. In this context, we propose the use of a simple indicator based on the CPI designed by Transparency International (2010). The role of CPI is to rank different nations on a basis of scale from 0 to 10 representing the degree of bribery of their governments, where 0 denotes very shady and 10 denotes fully clean. Despite CPI undoubtedly only takes into account bribery and not human rights abuses, it is questionably a rational alternative, as community fraud and human rights concerns are generally very much linked. In the context of this framework, we suggest to compute the human rights and fraud indicator as an average CPI of the nation such as South Africa involving in the life cycle of a power production system. This indicator will depend largely on firm sourcing plan, even if inexorably the technology can determine where the fuels and raw materials are sourced from. It is calculated according to the equation below: 


$$
C P I=\sum_{c}^{c} \frac{C P I_{c}}{C}(\text { score } 0-10)
$$

Where:

$$
\begin{array}{ll}
\checkmark & C P I \text { : Corruption Perceptions Index (score } 0-10) \\
\checkmark & C P I_{C} \text { : regarding country within the life cycle of a power plant } \\
\checkmark & C \quad \text { : overall amount of countries }
\end{array}
$$

\section{Conclusion}

In response to ever-increasing concerns regarding ecological degradation and societal impact, numerous stakeholders such as non-governmental organisations, government officials, end-users, the mass media, and community activists have compelled business organizations, particularly multi-national companies to lessen harmful greenhouse gases emissions associated with their production activities. Energy sector is one of the biggest harmful greenhouse gases emission producer, hence, decision-makers within the energy sector are forced to promote and build environmental friendly and sustainable power generation plants. To this end, the concept of sustainability in the electricity sector has attracted so much attention from academics and industrial practitioners over the last three decades. Albeit, an important number of sustainability assessment frameworks for electricity generating technologies are found in the current literatures, three major drawbacks have emerged from those frameworks. Firstly, there is a lack of a holistic and comprehensive sustainability assessment framework for different power generation plants. Secondly, from economic aspect, the most used model (Levelised Cost of Electricity) to measure the cost performance of various electricity generating technologies is biased and is not inclusive enough, because, it only considers the capital, Operations and Maintenance, and fuel costs. Hence, snubbing crucial elements to business decision. Lastly, in the current literature, there is no a single sustainability assessment model that considers all the phases of electrical energy's lifecycle. These gaps were identified through a thorough review of significant studies on the three sustainability pillars: environmental, economic, and social aspects, as well as on the system boundaries considered while performing these assessments (Appendixes A, B1, and B2). The review of current literature included both the sustainability assessments applied to power supply systems and those applied to other systems than energy systems. At least a set of 183 studies conducted in the electricity sector. It should be noted that only the best works that have been published in the recognised international journals were reviewed for both studies associated with power sector and other than electricity sector. The result of critical review of the 183 previous studies demonstrated that $77 \%$ of studies performed in electricity sector focused separately either on economic, environmental, or social aspects of power plants, while $7 \%$ attempted to combined only two aspects, and only $16 \%$ of the works attempted to incorporate all the three sustainability pillars into one framework. Furthermore, the result of critical review of previous studies indicate significant gaps at the level of the system boundaries considered during the sustainability assessment.

Thus, to address the above flaws, the present study makes the following contributions to sustainability assessment of electricity supply system body of knowledge:

- $\quad$ First, by reviewing an extensive amount of studies concerning sustainability analysis in energy sector, the present study produces an improved understanding of how current literatures measure sustainability of power generation plants.

- This study has developed a novel comprehensive economic analysis model for measuring the economic performance of different power generation plants.

- $\quad$ The present study has developed a holistic and integrated sustainability assessment framework through a selection of a set of sustainability analysis measures from the literature and processing them by means of an-in-depth critical analysis of existing literatures. After that, a set of Considering these flaws, this study contributes to the current body of knowledge on sustainability in energy sector by developing a new, holistic sustainability assessment framework for power generation plants. The developed model includes 19 impact categories, 52 potential indictors, and 10 end points environmental, economic, and social aspects.

- $\quad$ The developed model can be employed as a decision-making means at the initial phases of the electricity producing plant development process.

- Additionally, it can enable decision-makers in energy sector to identify the source and sustainability concerns during the whole power generation plant's life cycle and offering the measures to improve assessment and debate concerning the sustainability issues. Furthermore, the constructed framework 
could also be employed as an outline structure regarding a broad assortment of sustainability appraisal approaches and tools. For example, multi-criteria decision analysis or sustainability accounting approaches. To sum up, the developed framework can be employed as blueprint concerning the critical elements that should be measured within a comprehensive sustainability analysis of power generation plants and allowing the selection of factors to consider within the decision-making process. 


\section{Appendix A. Distribution of literature review papers based on one sustainability dimension}

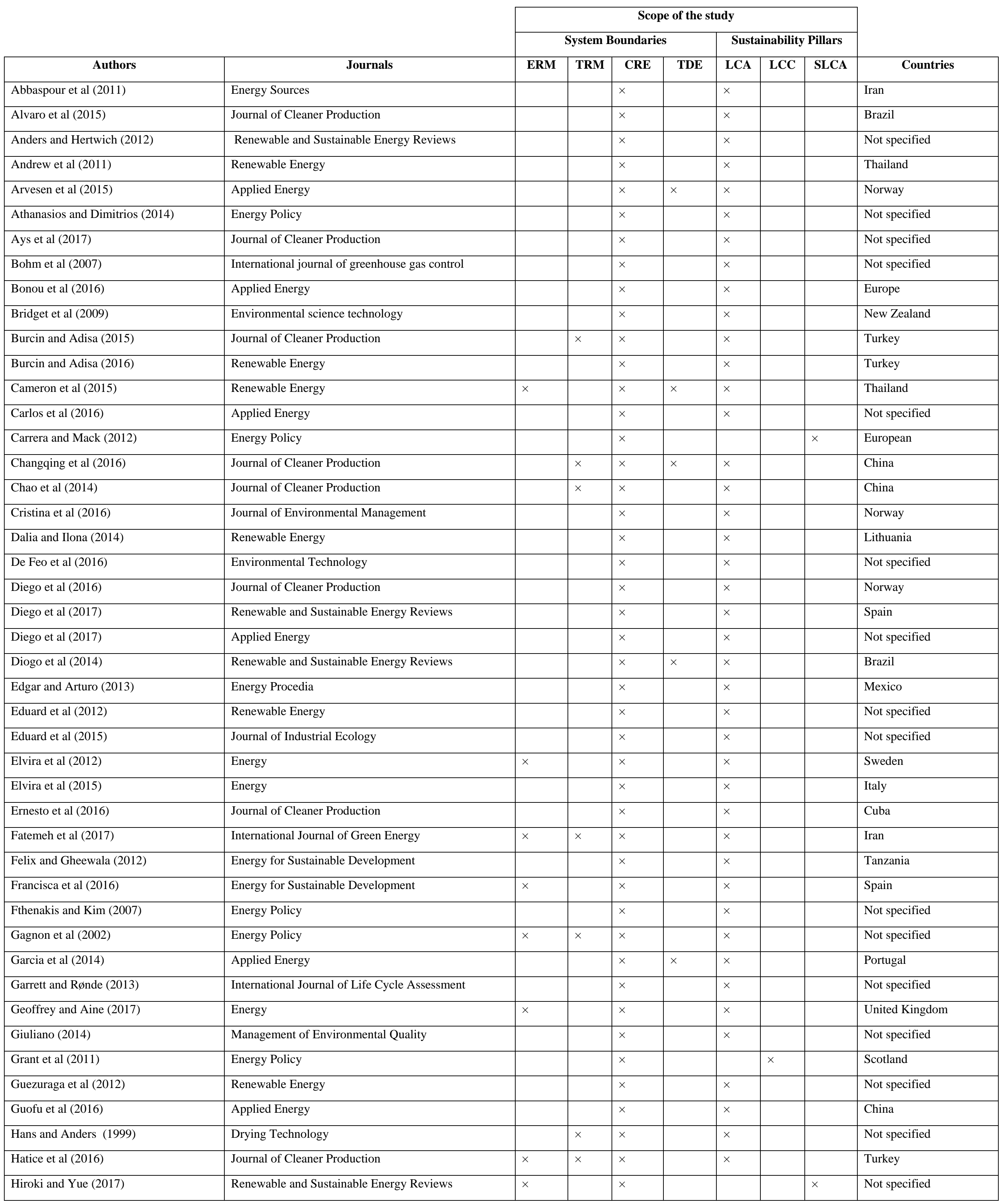




\begin{tabular}{|c|c|c|c|c|c|c|c|c|}
\hline Hondo (2005) & Energy & $x$ & & $x$ & & $x$ & & Japan \\
\hline Hrayshat (2009) & Energy Sources & & & $x$ & & & $x$ & Jordan \\
\hline Ishan and Pallav (2017) & Renewable and Sustainable Energy Reviews & & & $x$ & & & $x$ & Not specified \\
\hline Ivan et al (2016) & Journal of Cleaner Production & & & $x$ & & & $x$ & Brazil \\
\hline Janie and Anthony (2017) & Applied Energy & & & $x$ & & $x$ & & Not specified \\
\hline Jelena et al (2012) & Management of Environmental Quality & & & $x$ & & $x$ & & Latvia \\
\hline Jin and Bin (2016) & Applied Energy & $x$ & $x$ & $x$ & $x$ & $x$ & & Not specified \\
\hline João et al (2015) & Energy Policy & & & $x$ & & $x$ & & Not specified \\
\hline John et al (2011) & Environmental Science Technology & & & $x$ & & $x$ & & United States \\
\hline Juliana et al (2016) & IJournal of Energy and Environment & $x$ & $x$ & $x$ & & $x$ & & Brazil \\
\hline Jungbluth et al (2005) & Journal of Life Cycle Assessment & & & $x$ & & $x$ & & Not specified \\
\hline Justin et al (2010) & Electric Power Systems Research & & & $x$ & & $x$ & & Portugal \\
\hline Karin and Christian (2016) & Renewable and Sustainable Energy Reviews & $x$ & & $x$ & & $x$ & & UAE \\
\hline Karin et al (2014) & Energy Policy & $x$ & & $x$ & & $x$ & & Europe \\
\hline Kathrin et al (2013) & Journal of Greenhouse Gas Control & & & $x$ & & $x$ & & Europe \\
\hline Kerstin and Sergio (2013) & Renewable Energy & & & $x$ & & $x$ & & Brazil \\
\hline Khan et al (2005) & Renewable Energy & & & $x$ & & $x$ & & Not specified \\
\hline Krishnaiah et al (2012) & Energy Sources & & & $x$ & & & $x$ & India \\
\hline Kuldeep et al (2014) & Environmental development & $x$ & & $x$ & $x$ & $x$ & & Not specified \\
\hline Lakhani et al (2014) & Applied Energy & & & $x$ & & $x$ & & United States \\
\hline Lamnatou and Chemisana (2017) & Renewable and Sustainable Energy Reviews & & & $x$ & & $x$ & & Not specified \\
\hline Le Quyen and Anthony (2016) & Procedia CIRP & & & $x$ & & $x$ & & Vietnam \\
\hline Letitia and Calin-Cristian (2017) & Journal of Cleaner Production & $x$ & $x$ & $x$ & & $x$ & & Not specified \\
\hline Letitia et al (2017) & Journal of Cleaner Production & $x$ & & $x$ & & $x$ & & Not specified \\
\hline Longlong et al (2014) & Energy Procedia & & $x$ & $x$ & & $x$ & & Japan \\
\hline Luis et al (2015) & Energy for Sustainable Development & & & $x$ & & $x$ & & Chile \\
\hline Manfred (2008) & Energy Conversion and Management & & & $x$ & & $x$ & & Not specified \\
\hline Marco and Enrica (2016) & Energy Policy & & & $x$ & & $x$ & & United Kingdom \\
\hline Marios et al (2016) & Solar Energy Materials \& Solar Cells & $x$ & & $x$ & & $x$ & & Not specified \\
\hline Martinez et al (2009) & Renewable Energy & & & $x$ & & $x$ & & Not specified \\
\hline Maxim (2014) & Energy Policy & $x$ & & $x$ & & $x$ & & Not specified \\
\hline Meier et al (2005) & Energy Policy & & & $x$ & & $x$ & & United States \\
\hline Messagie et al (2014) & Applied Energy & $x$ & & $x$ & & $x$ & & Belgium \\
\hline Michael et al (2013) & Environmental science technology & & & $x$ & & $x$ & & United States \\
\hline Ming et al (2016) & Renewable and sustainable energy reviews & & & $x$ & & $x$ & & China \\
\hline Mirko and Riccardo (2014) & Journal of Cleaner Production & & & $x$ & & $x$ & & Italy \\
\hline Morrison and jay (2017) & Journal of Cleaner Production & $x$ & & $x$ & $x$ & $x$ & & United States \\
\hline Murat and Mustafa (2009) & Applied Energy & & & $x$ & & & $x$ & Turkey \\
\hline Murat and Omer (2011) & Energy & & & $x$ & & $x$ & & Not specified \\
\hline Naser and Timothy (2008) & Energy Policy & & & $x$ & & $x$ & & Not specified \\
\hline Nelson et al (2006) & Renewable Energy & & & $x$ & & & $x$ & Not specified \\
\hline Ning et al (2017) & Resources, Conservation and Recycling & $x$ & & $x$ & $x$ & $x$ & & China \\
\hline Nishimura et al (2010) & Applied Energy & & & $x$ & & $x$ & & Japan and China \\
\hline Oliveira et al (2015) & Energy Conversion and Management & & & $x$ & & $x$ & & Belgium \\
\hline Onat and Bayar (2010) & Renewable Sustainable Energy Reviews. & & & $x$ & & $x$ & & Not specified \\
\hline Parrado et al (2015) & Energy & & & $x$ & & & $x$ & Chile \\
\hline Paudel and Sarper (2013) & Energy & & & $x$ & & & $x$ & United States \\
\hline Paul et al (2012) & Energies & & & $x$ & & $x$ & & Australia \\
\hline Pehnt (2006) & Renewable Energy & & & $x$ & & $x$ & & Not specified \\
\hline Pehnt and Henkel (2009) & Journal of Greenhouse Gas Control & $x$ & & $x$ & & $x$ & & Not specified \\
\hline
\end{tabular}




\begin{tabular}{|c|c|c|c|c|c|c|c|}
\hline Pehnt et al (2008) & Energy & & $x$ & $x$ & $x$ & & Germany \\
\hline Peishi et al (2017) & Energy Procedia & & $x$ & $x$ & $x$ & & Not specified \\
\hline Peng et al (2013) & Renewable and Sustainable Energy Reviews & & $x$ & $x$ & $x$ & & Not specified \\
\hline Ravi and Bhat (2010) & International Journal of Green Energy & & $x$ & $x$ & $x$ & & India \\
\hline Ravina et al (2015) & Journal of Cleaner Production & & $x$ & $x$ & $x$ & & Mauritius \\
\hline Rita et al (2014) & Applied Energy & & $x$ & $x$ & $x$ & & Portugal \\
\hline Rongrong et al (2016) & Energy Conversion and Management & & $x$ & $x$ & $x$ & & Not specified \\
\hline Samiha and Bryan (2017) & 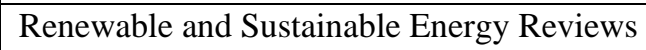 & & $x$ & $x$ & $x$ & & Not specified \\
\hline Santoyo-Castelazo et al (2011) & Energy & & $x$ & $x$ & $x$ & & Mexico \\
\hline Santoyo-Castelazo et al (2014) & Energy Conversion Management & & $x$ & $x$ & $x$ & & Mexico \\
\hline Sara et al (2017) & Renewable and Sustainable Energy Reviews & & $x$ & $x$ & $x$ & & Canada \\
\hline Sastre et al (2015) & Applied Energy & $x$ & $x$ & $x$ & $x$ & & Spain \\
\hline Sean et al (2015) & Journal of Energy Storage & & $x$ & $x$ & $x$ & & Canada \\
\hline Seyed et al (2015) & J. Human and Ecological Risk Assessment & & $x$ & $x$ & $x$ & & Iran \\
\hline Sheng et al (2016) & Energy Conversion and Management & & $x$ & $x$ & $x$ & & China. \\
\hline Slobodan et al (2016) & Energy Sources & & $x$ & $x$ & $x$ & & Serbia \\
\hline Stacey and Garvin (2012) & Journal Industrial Ecology & & $x$ & $x$ & $x$ & & Not specified \\
\hline Stephanie et al (2010) & Energy & $x$ & $x$ & $x$ & $x$ & & Not specified \\
\hline Suat and iftcioglu (2013) & international journal of hydrogen energy & & $x$ & $x$ & $x$ & & Not specified \\
\hline Talavera et al (2017) & Energy & & $x$ & $x$ & $x$ & & Europe and USA \\
\hline Thu and John (2015) & S. Energy Technologies and Assessments & & $x$ & $x$ & $x$ & & Denmark \\
\hline Tomasini et al (2017) & Applied Thermal Engineering & & $x$ & x & $x$ & & Not specified \\
\hline Tomoki and Toru (2015) & Applied Energy & & $x$ & $x$ & $x$ & & Japan \\
\hline Tonini and Thomas (2012) & Applied Energy & & $x$ & $x$ & $x$ & & Denmark \\
\hline Toolseeram (2008) & Journal of Cleaner Production & & $x$ & x & $x$ & & Mauritius \\
\hline Toshiyuki and Mika (2015) & Energy Economics & & $x$ & x & $x$ & & United States \\
\hline Turconi et al (2013) & Renewable and Sustainable Energy Reviews & $x$ & $x$ & $x$ & $x$ & & Not specified \\
\hline Turconi et al (2014) & Journal of Life Cycle Assessment & & $x$ & $x$ & $x$ & & Denmark \\
\hline Turconi et al (2014) & Applied Energy & $x$ & $x$ & $x$ & $x$ & & Ireland \\
\hline Turconi, et al (2014) & Applied Energy & $x$ & $x$ & $x$ & $x$ & & Denmark \\
\hline Valentina et al (2015) & Biomass and Bioenergy & $x$ & $x$ & x & $x$ & & Italy \\
\hline Vargas et al (2015) & Applied Thermal Engineering & $x$ & & & $x$ & & Mexico \\
\hline Viebahn and Nitsch (2007) & journal of greenhouse gas control & & $x$ & $x$ & $x$ & & Germany \\
\hline Vuk et al (2016) & Energy Conversion and Management & & $x$ & $x$ & $x$ & & Serbian \\
\hline Wang and Sun (2012) & Renewable Energy & & $x$ & x & $x$ & & Not specified \\
\hline Wei-Cheng and Heng-Yi (2017) & Journal of Cleaner Production & & $x$ & x & $x$ & & Taiwan \\
\hline Xiaoyu et al (2011) & Applied Energy & & $x$ & $x$ & $x$ & & China \\
\hline Yaw et al (2014) & 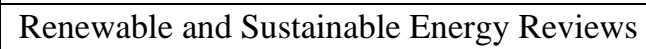 & & $x$ & x & $x$ & & Not specified \\
\hline Yemane et al (2017) & Applied Energy & & $x$ & x & $x$ & & Canada \\
\hline Yemane et al (2017) & Journal of Cleaner Production & & $x$ & x & & $x$ & Not specified \\
\hline Yuan et al (2015) & Energy & $x$ & $x$ & $x$ & $x$ & & China \\
\hline Yu-Fong et al (2017) & Renewable Energy & & $x$ & $x$ & $x$ & & Not specified \\
\hline 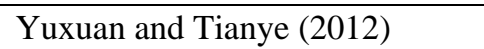 & Renewable Energy & & $x$ & $x$ & $x$ & & China \\
\hline Zhao et al (2015) & Energy & & $x$ & $x$ & & $x$ & China \\
\hline Zhao et al (2016) & Energy Sources & & $x$ & $x$ & & $x$ & China \\
\hline Zhiqiang et al (2017) & Applied Energy & & $x$ & $x$ & $x$ & & China. \\
\hline
\end{tabular}




\section{Appendix B.1. Distribution of literature review papers based on two sustainability dimensions}

\begin{tabular}{|c|c|c|c|c|c|c|c|c|c|}
\hline & \multirow[b]{4}{*}{ Journals } & & & & & & & & \multirow{4}{*}{ Countries } \\
\hline \multirow[b]{3}{*}{ Authors } & & \multicolumn{7}{|c|}{ Scope of the study } & \\
\hline & & \multicolumn{4}{|c|}{ System Boundaries } & \multicolumn{3}{|c|}{ Sustainability Pillars } & \\
\hline & & ERM & TRM & CRE & TDE & LCA & LCC & SLCA & \\
\hline Amit et al (2017) & Applied Energy & & & $x$ & & $x$ & $x$ & & United Kingdom \\
\hline Carla et al (2017) & Desalination & & & $x$ & $x$ & $x$ & $x$ & & Not specified \\
\hline Carlo et al (2016) & Energy Policy & & & $x$ & & $x$ & $x$ & & United States \\
\hline Carlo et al (2015) & Energy Conversion and Management & & & $x$ & & $x$ & $x$ & & Not specified \\
\hline Carlos et al (2016) & Applied Energy & & & $x$ & & $x$ & & & Not specified \\
\hline David et al (2017) & Applied Energy & & & $x$ & & $x$ & $x$ & & Not specified \\
\hline Gujba et al (2010) & Energy Policy & & & $x$ & & $x$ & $x$ & & Nigeria \\
\hline Kannan et al (2007) & Renewable and Sustainable Energy Reviews & & & $x$ & & $x$ & $x$ & & Singapore \\
\hline Kathrin et al (2016) & International Journal of Greenhouse Gas Control & & & $x$ & & $x$ & $x$ & & Swiss \\
\hline Miro et al (2013) & Energy & & & $x$ & & $x$ & $x$ & & Not specified \\
\hline Sören et al (2010) & Journal of Environmental Planning and Management & & & $x$ & & $x$ & $x$ & & Germany \\
\hline Xiaolong et al (2014) & $\begin{array}{l}\text { Journal of Cleaner Production } \\
\end{array}$ & & & $x$ & & $x$ & $x$ & & China \\
\hline Xiaoye et al (2013) & Journal of Cleaner Production & $x$ & $x$ & $x$ & & $x$ & $x$ & & China \\
\hline
\end{tabular}

Appendix B.2. Distribution of literature review papers based on three sustainability dimensions

\begin{tabular}{|c|c|c|c|c|c|c|c|c|c|}
\hline \multirow[b]{3}{*}{ Authors } & \multirow[b]{3}{*}{ Journals } & \multicolumn{7}{|c|}{ Scope of the study } & \multirow[b]{3}{*}{ Countries } \\
\hline & & \multicolumn{4}{|c|}{ System Boundaries } & \multicolumn{3}{|c|}{ Sustainability Pillars } & \\
\hline & & ERM & TRM & CRE & TDE & LCA & LCC & SLCA & \\
\hline Alexandru (2014) & Energy Policy & & & $x$ & & $x$ & $x$ & $x$ & Not specified \\
\hline Ángel et al (2016) & Computers and Chemical Engineering & & & $x$ & & $x$ & $x$ & $x$ & Not specified \\
\hline Araujo et al (2013) & Energy & & & $x$ & & $x$ & $x$ & $x$ & Portugal \\
\hline Barry (2017) & Energy Procedia & & & $x$ & & $x$ & $x$ & $x$ & Not specified \\
\hline Begic' and Afgan (2007) & Energy & & & $x$ & & $x$ & $x$ & $x$ & Bosnia-Herzegovina \\
\hline Burcin and Adisa (2016) & Energy Policy & & & $x$ & & $x$ & $x$ & $x$ & Turkey \\
\hline Burcin and Adisa (2017) & Sustainable Production and Consumption & & & $x$ & & $x$ & $x$ & $x$ & Turkey \\
\hline Cebi et al (2009) & Energy & $x$ & & $x$ & & $x$ & $x$ & $x$ & Not specified \\
\hline Elghali et al (2007) & Energy Policy & & & $x$ & & $x$ & $x$ & $x$ & Not specified \\
\hline Evans et al (2009) & Renewable Sustainable Energy Reviews & & & $x$ & & $x$ & $x$ & $x$ & Not specified \\
\hline Heidi et al (2017) & Energy & & & $x$ & & $x$ & $x$ & $x$ & Germany \\
\hline Hong et al (2013) & Energy & & & $x$ & & $x$ & $x$ & $x$ & South Korea \\
\hline Irene et al (2017) & Journal of Cleaner Production & $x$ & & $x$ & & $x$ & $x$ & $x$ & Mexico \\
\hline Jonathan and Klaus (2007) & Energy Policy & & & $x$ & & $x$ & $x$ & $x$ & Not specified \\
\hline Juan et al (2015) & Energy & $x$ & & $x$ & & $x$ & $x$ & $x$ & Not specified \\
\hline Laurence and Adisa (2011) & Energy & & & $x$ & & $x$ & $x$ & $x$ & United Kingdom \\
\hline Laurence and Adisa (2014) & Energy for Sustainable Development & & & $x$ & & $x$ & $x$ & $\times$ & United Kingdom \\
\hline Mario et al (2017) & Journal of Cleaner Production & & & $x$ & & $x$ & $x$ & $x$ & Not specified \\
\hline May et al (2006) & Process Safety Environmental Protection & $x$ & $x$ & $x$ & $x$ & $x$ & $x$ & $x$ & Not specified \\
\hline Mihály et al (2014) & Energy Policy & & & $x$ & & $x$ & $x$ & $x$ & Not specified \\
\hline Naim \& Maria (2002) & Energy & & & $x$ & & $x$ & $x$ & $x$ & Not specified \\
\hline Omann et al (2009) & European Journal of Operational Research & & & $x$ & & $x$ & $x$ & $x$ & Austria \\
\hline Santoyo-Castelazo et al (2014) & Journal of Cleaner Production & & & $x$ & & $x$ & $x$ & $x$ & Mexico \\
\hline Sharon and Stephanie (2015) & Energy Policy & $x$ & & $x$ & & $x$ & $x$ & $x$ & United States \\
\hline Stamford and Azapagic, (2012) & International Journal Energy Res & $x$ & & $x$ & & $x$ & $x$ & $x$ & United Kingdom \\
\hline Tarun and Balachandra (2015) & Applied Energy & & & $x$ & & $x$ & $x$ & $x$ & Indian \\
\hline Thomas (2013) & Energy & & & $x$ & & $x$ & $x$ & $\times$ & Not specified \\
\hline Thomas et al (2007) & Energy Policy & & & $x$ & & $x$ & $x$ & $x$ & Uganda. \\
\hline Widodo and Nok (2016) & Renewable Energy & & & $x$ & & $x$ & $x$ & $x$ & Indonesia \\
\hline
\end{tabular}




\section{References}

Abbaspour M., Monavari M., Karbassi A \& Kargari N.2011. Nuclear Power and Its Role in CO2 Emissions from the Electricity Generation Sector in Iran, Energy Sources, Part A: Recovery, Utilization, and Environmental Effects, 34:1, 43-52, DOI: 10.1080/15567036.2010.483532

Adams, B., Kennedy, A., \& Sahely, R.2005. Developing sustainability criteria for urban infrastructure systems. Journal of Civil Engineering, 32, 72-85.

Akadiri, P., Olomolaiye, P., \& Chinyio, E.2013. Multi-criteria evaluation model for the selection of sustainable materials for building projects. Automation in Construction, 30, 113-125

Alexandru M.2014. Sustainability assessment of electricity generation technologies using weighted multi-criteria decision analysis. Energy Policy 65, 284-297

Alvaro R, Edson B , Raphael M.2015. A life cycle assessment of the Brazilian coal used for electric power generation. Journal of Cleaner Production 92,179-186

Amit B, Richard H, Paul F, William R, Nilay S, Niall M,John D, Markus K, Mohammed P, Mathieu I, Jenny J, Nigel B, Ausilio B, Corinne B, Andrew S, Jethro A. 2017. Screening and techno-economic assessment of biomassbased power generation with CCS technologies to meet 2050 CO2 targets. Applied Energy 190, 481-489

Andhra P, India K, Suresh J, Arvind K, Sunil D.2014. A life cycle environmental impact assessment of natural gas combined cycle thermal power plant in. Environmental Development 11, 162-174

Andrew P, Tania U, Andrew M.2011. Life cycle assessment of a community hydroelectric power system in rural Thailand. Renewable Energy 36, 2799-2808

Ángel G., Gonzalo G., Laurence S., Adisa A.2016. Enhanced data envelopment analysis for sustainability assessment: A novel methodology and application to electricity technologies, Computers and Chemical Engineering 90, 188-200

Annette E, Vladimir S, Tim J.2009. Assessment of sustainability indicators for renewable energy technologies. Renewable and Sustainable Energy Reviews 13, 1082-1088

Araújo M, Ribeiro F, Ferreira P,. 2013. Evaluating future scenarios for the power generation sector using a multicriteria decision analysis (MCDA) tool: the Portuguese case. Energy 2013;52:126-36

Ariaratnam, S \& Koo, D.2008. Application of a Sustainability Model for Assessing Water Main Replacement Options. Journal of Construction Engineering and Management, 134, 8, 563-574.

Arvesen A, Hertwich E. 2012. Assessing the life cycle environmental impacts of wind power: a review of present knowledge and research needs. Renewable and Sustainable Energy Reviews 16, 5994-6006

Arvesen A., Ingrid B., Bernhard M., Edgar G.2015. Life cycle assessment of transport of electricity via different voltage levels: A case study for Nord-Trøndelag county in Norway. Applied Energy 157, 144-151

Arvidsson R, Kristin F, Morgan F, Magdalena S, Sverker M. 2012. "Energy Use Indicators in Energy and Life Cycle Assessments of Biofuels: Review and Recommendations.” Journal of Cleaner Production 31, 54-61.

Ays, e, Emrah O, Ihsan K., Hameed A. 2017. Life cycle assessment (LCA) of digested sewage sludge incineration for heat and power production, Journal of Cleaner Production 142, 1684-1692

Bohm M. 2007. Capture-ready coal plants - options, technologies and economics. International journal of greenhouse gas control, 1, 113-120.

Bonou , Alexis L, Stig I.2016. Life cycle assessment of onshore and offshore wind energy-from theory to application Alexandra. Applied Energy 180, 327-337

Bridget M. , Zeb J, Carol A. .2009.Comparison of Life Cycle Carbon Dioxide Emissions and Embodied Energy in Four Renewable Electricity Generation Technologies in New Zealand. Environ. Sci. Technol. 2009, 43, 64066413

Burcin A, Adisa A.2015. Life cycle environmental impacts of electricity from fossil fuels in Turkey Journal of Cleaner Production 106, 555-564 
Burcin A, Adisa A.2016. Renewable electricity in Turkey: Life cycle environmental impacts. Renewable Energy 89, 649-657

Cameron M, John B, Eric S, Amberli Y , Jessica S, Tiffany Y, Shabbir H.2015. Comparative Life Cycle Assessment of a Thai Island's diesel/PV/wind hybrid. Renewable Energy 80, 85-100

Carlo S, Adriana D, Paola C, Michela G, Emma B, Paola G.2015. Life Cycle Assessment and Life Cycle Costing of a SOFC system for distributed power generation Energy Conversion and Management 100, 64-77

Carrera D, Mack A. 2012.Sustainability assessment of energy technologies via social indicators: result of a survey among European energy experts. Energy Policy; 38:1030-9.

Changqing X., Jinglan H., Jianmei C., Xiaofei H., Chen L., Xiangzhi L.2016. Is biomass energy really clean? An environmental life-cycle perspective on biomass-based electricity generation in China Journal of Cleaner Production 133, 767-776

Chao F, Xuenong G, Yuting T, Yuansheng Z. 2014. Comparative life cycle environmental assessment of flue gas desulphurization technologies in China. Journal of Cleaner Production 68, 81-92

Cristina I, Carine L, Francesco C.2016. Life-cycle assessment of a biogas power plant with application of different climate metrics and inclusion of near-term climate forcers. Journal of Environmental Management 184, 517-527.

Dalia S, Ilona A.2014. External costs of electricity generation options in Lithuania. Renewable Energy 64 , 215224

De Feo G, Forni M, Petito F, Renno C. 2016. Life cycle assessment and economic analysis of a low concentrating photovoltaic system. Environmental Technology, 37:19, 2473-2482, DOI: 10.1080/09593330.2016.1152308

Diego G, Daniel G, Javier D.2017. Prospective life cycle assessment of the Spanish electricity production. Renewable and Sustainable Energy Reviews 75, 21-34

Diego G, Diego I, Daniel G.2017. Prospective analysis of energy security: A practical life-cycle approach focused on renewable power generation and oriented towards policy-makers Applied Energy 190, 891-901

Diego G, Diego I, Mario M, Javier D, Kari E, Arne L.2016. Integration of life-cycle indicators into energy optimisation models: the case study of power generation in Norway. Journal of Cleaner Production 112, 26932696

Diego G., Kari, E., Arne. L., Martin, K. 2016. The role of the discount rates in energy systems optimisation models. Renewable and Sustainable Energy Review, 59, 56-72. Available from www.sciencedirect.com

Diogo A, Ivete D, Mary L, Aldo R.2014. Life cycle assessment of the sugarcane bagasse electricity generation in Brazil. Renewable and Sustainable Energy Reviews 32, 532-547

Edgar R, Arturo M.2014. Optimizing the energy portfolio of the Mexican electricity sector by 2050 considering CO2eq emissions and Life Cycle Assessment. Energy Procedia 57, 850 - 859

Eduard C, Nicholas F., Sarah J., and Joule B. 2015. Sustainability of Rooftop Technologies in Cold Climates Comparative Life Cycle Assessment of White Roofs, Green Roofs, and Photovoltaic Panels, Journal of Industrial Ecology, DOI: 10.1111/jiec.12269

Eduard O, Antoni G, Alvaro d, Dieter B, Luisa F.2012. Comparative life cycle assessment of thermal energy storage systems for solar power plants. Renewable Energy 44, 166-173

Elvira B, Laura V, Alberto C, Sergio U.2015. Integrating life cycle assessment and emergy synthesis for the evaluation of a dry steam geothermal power plant in Italy Energy 86, 476-487

Elvira B, Pier P, Sergio U.2012. Assessing the environmental performance and sustainability of bioenergy production in Sweden: A life cycle assessment perspective. Energy 37, 69-78

Ernesto L, Elena R, Henri S, Osvaldo R, Steven De M, Dewulf J. 2016. A comparative assessment of anaerobic digestion power plants as alternative to lagoons for vinasse treatment: life cycle assessment and exergy analysis. Journal of Cleaner Production 113, 459-471. 
Fatemeh D, Majid S, Khosro A.2017. A well to wire LCA model development and sensitivity analysis for carbon footprint of combined cycle power plants in Iranian electricity network, International Journal of Green Energy, 14:5, 499-508, DOI: 10.1080/15435075.2017.1279618

Felix M; Gheewala S.2012. Environmental assessment of electricity production in Tanzania. Energy for Sustainable Development, 16, 439-447.

Francisca F, Carlos P, Mercedes R.2016. Life cycle assessment of biodiesel in Spain: Comparing the environmental sustainability of Spanish production versus Argentinean imports. Energy for Sustainable Development 33, 36-52

Fthenakis V, Kim HC. 2007. Greenhouse-gas emissions from solar electric- and nuclear power: a life-cycle study. Energy Policy; 35:2549-57

Gagnon, L., Belanger, C., \& Uchiyama, Y. 2002. Life-cycle assessment of electricity generation options: The status of research in year 2001. Energy Policy, vol. 30, no. 14, 1267-1278. 